\title{
Traces of occupancy and its effect upon burglars' residential target selection
}

\author{
Yongtae Chun, Ju-Lak Lee* \\ Dept. of Security Management, Kyonggi University, Suwon, South Korea
}

Email address:

julaklee@hanmail.net(Ju-Lak Lee)

\section{To cite this article:}

Yongtae Chun, Ju-Lak Lee, Traces of Occupancy and Its Effect upon Burglar's Residential Target Selection, Social Sciences. Vol. 2, No. 3, 2013, pp. 135-141. doi: 10.11648/j.ss.20130203.15

\begin{abstract}
Burglary is a type of crime that happens most frequently to ordinary citizens, and its consequences may include financial damage as well as serious psychological repercussions. In South Korea, burglary cases constituted 16.1 per cent of the total crimes reported in 2011, thus calling for viable preventive measures to alleviate the on-going problem. In this study, the authors examined the main situational factors that played a crucial role in burglars' decision making in selecting specific targets and executing their crime. The data collected from interviewing fifty-two burglary suspects detained at the Detention Centre at the Incheon Public Prosecutor's Office in South Korea was analysed to assess different situational factors that were mainly considered by them. The results indicated that the burglary suspects were more influenced by possible cost than gain. Furthermore, occupancy of residence was the most important factor in the decision making process utilised by the suspects.
\end{abstract}

Keywords: Burglary, Decision Making, Traces of Occupancy, Situational Factor

\section{Introduction}

Burglary is a crime that an ordinary citizen can encounter most frequently. According to the data provided by the Ministry of Justice in South Korea, 281,859 cases of theft occurred in 2011, which comprised 16.1 per cent of the total number of crime reported, and burglary took up 23.3 per cent of the theft, showing that it is the most common crime in the country.

One misconception about burglary is that its consequences may not be serious due to the absence of physical contact between the burglar and the victim. However, in addition to monetary damage, burglary leaves serious psychological repercussions and other negative impacts.

Understanding the way in which burglary impacts on its victims will demonstrate the need for preventive measures against this form of crime. Burglary has several different effects on its individual victims, as well as on society in general. Clarke and Hope point out that, "Burglary is a significant social problem which in various ways affects the lives of a great many people [1]." Maguire and Kynch identify a number of different forms of impact that residential burglary has on its victims [2]. Financial loss was the most immediate of these. According to the 1998
British Crime Survey, the loss from theft alone by household burglary in the UK, totalled $£ 590$ million, and the average loss from a burglary was $£ 1,400$. These financial losses were rarely covered by insurance because less than half of the burglary victims were insured [2]. Although the comparable numbers in South Korea cannot be confirmed without detailed statistical data, it is expected that the situation is worse than that of the UK.

However, according to this 2010 British survey, financial loss was not the only impact of burglary. Significant emotional reactions to the burglary, on the part of the victim, were also quite common. Amongst the most important forms of such reactions were post-traumatic stress disorder, feelings of anger, and desire for revenge. One of the key findings of the British Crime Survey 2010 was that the overall emotional impact was far greater on its victims in the case of burglary than it was for many other types of crime.

Therefore, in order to reduce the number of burglary and its damage, a deeper understanding of the crime is required and effective preventive measures must be suggested.

Most prior studies on burglary suggest that a burglar is a property offender who does not engage in dangerous or confrontational behaviour. For example, Scarr [3] claims that, "Burglary is an essentially passive crime in which the 
burglar tries to avoid any form of contact with the victim." Walsh [4] also suggests that the majority of burglars take special precautions against the possibility of a confrontation with a person within the home. Furthermore, numerous studies have concluded that burglars place the emphasis on whether someone is present in the house when choosing their targets [5], [6], [7], [8]. This research is conducted in an effort to analyse the importance of occupancy in burglars' target selection and their methods to check the occupancy of a residence through in-depth interviews and aims to provide viable policy implications.

\section{Research Methods}

Burglary victimisation does not appear to be a random event, but rather, one in which the offender deliberately selects a target according to certain situational criteria. Most people, however, rarely witness crimes, and even fewer witness the deliberations that lead to a crime being committed. The criminal situation and its decision making process, therefore, are best understood by examining offenders.

Burglary is not a random event that results from spontaneous acts of the offenders, but it usually occurs through a rational target selection process utilised by the offenders, and this decision making task can be understood most accurately by studying the those who actually have committed the crime.

The primary source of data was a selected sample from among suspects who were detained in the Detention Centre at the Incheon Public Prosecutor's Office. With the objective of exploring the decision making process of the burglars to be interviewed, the criteria of a purposive sampling method were used to select the burglar suspects that came to constitute the sample. Subjects were selected based on the crime for which they were being detained, and their records were reviewed in order to determine that each subject met the sample criteria.

The data examined in this study was collected from the detainees of the Detention Centre at the Incheon Public Prosecutor's Office in South Korea. Also, by using the purposive sampling method, the study subjects were chosen with a basis on the crime they were arrested for, burglary, and their records were carefully considered to confirm their suitability for the interviews; and Every burglar suspect selected was male and most of them, thirty-eight out of fifty-two (76.9 per cent), were local residents.

All of the subjects interviewed in the study were male and a high percentage of the subjects (37 out of 52 , or 71.2 per cent) were local. Thirty-eight out of fifty-two burglars (76.9 per cent) interviewed for the study, came from the research area (Incheon Metropolitan City, Korea).

Using the instrument of the semi-structured interview, fifty-two interviews were conducted and all interviews were audio-taped, in every case with the subject's prior permission. In terms of actually analysing the transcribed audio-tapes, the first level of analysis already began while the tapes were being listened to during transcription. The second level of analysis occurred when the process of transcription was completed. At this level, with each reading of the transcripts, 'units of information' were noted, key words were written in the margins, and passages of interest were colour highlighted. The highlighted passages were examined for both the commonalities and the disparities that emerged across the responses of the different individual subjects. The commonalities in the subjects' responses were then categorised under themes; and this 'categorisation' constituted the third level of analysis.

Despite the qualitative nature of the research in the study, the use of numbers and frequency counts were regarded as important techniques in the verification of the research expectations, and in the subsequent process of trying to make judgements with respect to the agreement or disagreement of variables across the subject interviews. According to Huberman and Miles [9], judgements involving 'number of times' and 'consistency' that are made almost unconsciously by a researcher during the analysis phase of their research, are based on counting. However, Creswell [10] is of the opinion that not all qualitative data should be converted into quantitative form, although he believes that if a researcher needs to make statements about frequencies, it is better to use numbers. This study supports Creswell's view that not all qualitative data are suitable for quantification, and thus considered, for instance, that the unique features of a given case could not be quantified, even though those features might be used to support a specific theoretical proposition [10].

\section{Research Findings}

\subsection{Reasoning Applied to Specific Target Selection}

When burglars are searching for a prospective target, they have to decide on a suitable area for their search, and further, to select a specific residence to burgle within that area. Maguire and Kynch suggested that in respect of the decision to burgle, the initial choice made by the burglars is their selection of the area in which the burglary is to take place [2]. This suggestion was borne out by research done by Bernasco and Nieuwbeerta who found that once the area had been established, then the burglars would select a target residence within that specific area to burgle [7].

When asked about the reasons for choosing their particular targets which is considered the second stage of the decision making, several common responses were given (analysed in the Table 1 below).

It was revealed that the burglars made their decisions based on the assessment of the situational risks associated with possible targets; the interviewees stated that after going through cost-benefit analysis, they excluded the residences that were perceived to pose greater risks than the expected gain. Specifically, most commonly mentioned situational risk factors included occupancy, detectability, 
and physical barriers.

Table 1. Reasons given by the study subjects for selecting a specific target residence

\begin{tabular}{ccl}
\hline Category of Factor & $\begin{array}{c}\text { Frequenc } \\
\mathbf{y}\end{array}$ & $\begin{array}{l}\text { Cues related to the } \\
\text { category of factor } \\
\text { (cited by the subjects) }\end{array}$ \\
\hline Absence of residents & $36 \quad \begin{array}{l}\text { - No signs of occupants } \\
\text { (afraid of making contact } \\
\text { with the residents) } \\
\text { - Visited the house before }\end{array}$ \\
Prior knowledge & $29 \quad \begin{array}{l}\text { - Information from others } \\
\text { - Knowledge of movement } \\
\text { of potential victims }\end{array}$ & $\begin{array}{l}\text { patterns of the residents } \\
\text { - Signs of affluence }\end{array}$ \\
Affluence of residence & $21 \quad \begin{array}{l}\text { Low surveillance } \\
\text { neighbours or onlookers in } \\
\text { sight) }\end{array}$ \\
Low detectability & 15 & $\begin{array}{l}\text { - The street very quiet } \\
\text { - No alarm system } \\
\text { - No surveillance cameras } \\
\text { - No barking dogs (especially } \\
\text { during the night) } \\
\text { - No deadbolt locks } \\
\text { - Absence of good lighting }\end{array}$ \\
\hline Absence of physical & 11 &
\end{tabular}

Using numerous methods to check the presence of the residents, the subjects (mentioned by thirty-six interviewees) considered occupancy as the most important situational factor in their target selection processes.

\subsection{Significance of Residents' Occupancy in Burglary Prevention}

For the subjects in the present study, the most important part of the process of carrying out a burglary was making sure that no one was at home. While being asked how they chose a house to break into, the subjects made frequent comments about the need for the house to be empty before they would operate. Almost nine out of ten subjects in the study sample ( 88.5 per cent) said that they would never intentionally go into a house which had somebody in it at the time of the burglary. These insights and responses offered by the subjects, made it clear that residences were more at risk of being targeted for burglary when the residents were away from home.

I have never broken into a house while someone is in. I am very scared of being caught by the resident in the house. I am always trying to make sure nobody is home. (Respondent 41)

I waited until the householders went to the market. When they were at the market, I was at their house to clean up. When householders go to the market, there is hardly anybody there during the day. (Respondent 3)

It is not easy to tell if people are in the house or not. If I have a feeling that somebody is there, I just do not go there. I do not take the unnecessary chance that somebody is there. (Respondent 24)

This practice of only burgling a home if there was nobody present in it, was confirmed by an analysis of the relevant police statistics. According to the Incheon Police Department burglary statistics for 2011, the number of burglaries occurring peaked on Tuesday and Wednesday, with the lowest number taking place on Saturday and Sunday.

Many studies have suggested that residential burglary is a weekday occurrence. A possible explanation for this phenomenon would be that residents go to work on weekdays, leaving their homes unattended at that time. In general, subjects in this study also preferred weekdays for committing burglary. The easiest opportunities for them, in relation to any residence, were on weekdays during the school term. In many households in Korea, both parents work outside the home during the day, so that if the children are also at school at that time, the house is usually left unoccupied. Thus, the typical burglary is most likely to occur during daytime hours that correspond to normal work hours and school time [12], [13], [14], [15], [3].

On the weekend, people usually are not burgled. It happens during the week, because [then] parents are working and the kids are gone to school. (Respondent 12)

If a criminal were going to burgle you, he would probably burgle a house on a weekday in the daytime. Residents are out working, and neighbours are not going to suspect anybody during the broad daylight. (Respondent 31)

According to Johnson and Bowers [12], most burglars operate between 6:00-12:00, with very few doing their work after midnight; and Scarr [3] found that the risk periods for burglary occurring were between 10:30-12:00 and 13:30-15:00. In the present study, the risk periods for burglary were found to generally correspond with the hours in those previous studies. The subject interviews revealed two time periods when residences were most at risk from burglary: 9:00-12:00, and 12:00-15:00 (see Figure 1 below). These risk periods for burglary coincided with the period of the day when, in most cases, residents were away at work, and children were at school or a day-care centre. In the past, in Korea, residential burglary was considered a nocturnal phenomenon. The change from that situation, as reflected in the data just cited, is generally attributable to the increase in women working outside the home in the daytime, a development that results in houses being left vacant for much of the day. Subjects in this study clearly favoured burglary times when the home was most likely to be empty; that is, they adjusted their work patterns to their targets' lifestyle.

Further, in reference to the relation between occupancy and residential vulnerability to burglary, there also seemed to be a connection between the season of the year and incidents of burglary. According to the Incheon Police Department burglary statistics for 2011, the incidence of burglary was spread evenly throughout the year, with the exception of two apparent peak periods. One such peak period was in the months of December and January, when 23 per cent of the burglaries for that year occurred; and the other peak period was in the months of July and August, 
when 19 per cent of the burglaries for the year occurred. Those months could be regarded as the period when residents were most likely to be away on holiday, and a correlation between this factor and the higher relative incidence of burglary during those months, seems very possible.

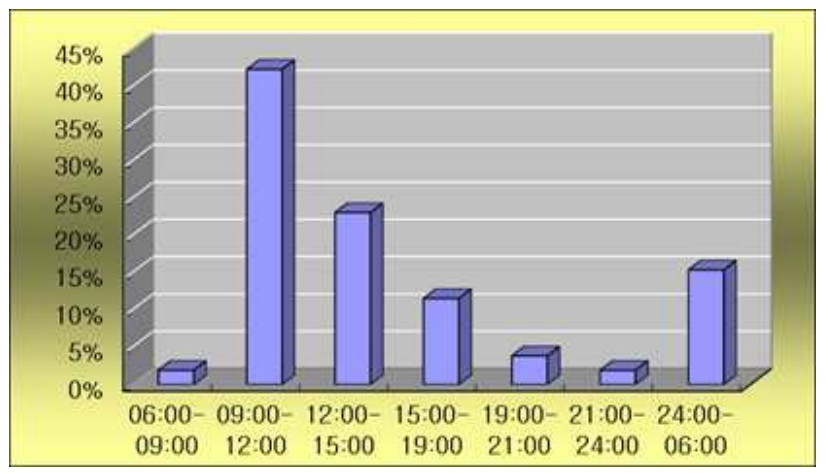

Figure 1. Subjects' preferred burglary times

One of the most consistent findings of the research that has been done on the influence of situational conditions on burglary is that burglars prefer unoccupied residences as targets. For example, data from the British Crime Survey on residential burglary, between 1997 and 1999 reveals that occupied residences are unlikely to be targets for burglary [7]. Further, Hearnden and Magill [8] found a much higher burglary rate among dwellings with a low occupancy rate than among dwellings with a high occupancy rate. Bennett and Wright reported that over 90 per cent of the burglars in their study indicated that occupancy of a building put them off attempting burglary at that target site [16]. Convicted burglars interviewed by Maguire and Bennett also stated that occupancy was a factor, in connection with the selection of a target, and that burglars prefer avoiding confrontations during burglary by selecting target homes that are, or appear to be, unoccupied [17]. In Wright and Decker's study of residential burglary, occupancy constituted the major risk factor associated with burglars' decisions not to enter a potential target residence. Also, Wright and Decker found that a small number of burglars would watch the occupants of a residential target come and go, in order to learn the patterns of the occupants' daily routine. Those burglars claimed, by this means, to be able to gain a full cognisance of the schedules kept by the occupants, and to have a clear idea as to how long the occupants would be away from their homes [18].

In the present study, the vast majority of the subjects (86.5 per cent) reported that they checked whether a target residence was free of occupants before entering.

When I select a target, I always make sure nobody is inside it. If there are lights on, or the sound of TV, I will pass it by. I know that many people leave lights and TV on when they go out, but even so, I do not take the risk of checking occupancy in those circumstances. (Respondent 20)

You never know whether there are people in the house until you check it. You just go and check it. You knock hard on the door and if nobody answers the door, it means nobody is in there. If somebody answers, you say, "I'm looking for so-and- so," or something like that. When you knock on the door, you have to have a real good reason all the time. (Respondent 16)

If there is mail in the mailbox and it is evening time, I know there is nobody in the house. Otherwise they would pick up their mail. But I still ring the doorbell to make sure there is really nobody there. (Respondent 46)

Although subjects took steps to avoid breaking into an occupied house, they occasionally found people inside who had not heard the ring of the doorbell or the sound of entry. In these cases, the subjects usually got out of the house immediately.

A friend of mine and I went into a house. It was broad daylight and we knocked on the door for a while. Nobody answered, and we thought that there was nobody in there. So I broke the window and went in through it. Then I opened the door for my friend. We started looking to see what there was. Then my friend passed by me and said to me that there was a person asleep in the bedroom. He [the person in the bedroom] must have not heard the doorbell. I just ran out of the place as fast as possible.... We took nothing from the house. (Respondent 15)

In one job I did, I broke into a house, believing there was nobody in the house. But I saw a resident sleeping on the couch. I left the house immediately. It was the scariest moment in my life. Since then I have always double-checked if the residents are home. (Respondent 21)

In the present study, the single biggest deterrent to non-selection of a residential burglary target was if people were actually home and the offender was aware of the fact. However, the effectiveness of even so formidable a deterrent as this, was qualified in the case of several subjects. In fact, six of the subjects specifically stated that they did not mind people being in the house at the same time as they broke into it. Four of these subjects often broke into houses while the occupants were asleep at night. All four of them belonged to the older offender group in the study sample. They claimed that there was an advantage to this practice of burgling the residence while the occupants were asleep inside. It gave them the opportunity to get the occupants' wallets that were with the latter's personal belongings in the bedroom. This rationale points to the older and more experienced subjects being drawn to targets with a promising return, and in such cases, being more willing to take extra risks for the possibility of greater reward, than were the younger and more inexperienced subjects.

I didn't mind people being in the house when I broke in. In fact, I broke in when the residents were home, on purpose, because I could get their wallets in the bedrooms. I always looked for cash, because I did not want to go through the hassle of selling stolen goods. Burglars often are busted with stolen goods and I wanted nothing on me. (Respondent 34) 
It is the most direct route to money. I do not like handling and dealing with merchandise.... I normally get to a house at two or three in the morning. That is when the people are in their deepest sleep. (Respondent 28)

When you steal merchandise, you have to sell it; whereas I steal money, and the job is done. (Respondent 8)

Another reason given by this sub-group of four subjects for selecting occupied residential targets, pertains to their fear of being given away by associates, and thus of being caught. This fear was because of the fact that, as one subject put it, "other people know your business and there's always some rats in the crowd" (Respondent 37). If a burglary involved stealing items (other than money), the stolen goods had to be sold or fenced. Fencing merchandise meant that the fence, the fence's associates, and even prospective buyers of the merchandise, might know the identity of the perpetrator of the burglary. The four subjects here claimed that having so many third parties involved increased the chances of them being caught by the police. On the other hand, acting solo, and focusing on stealing wallets while the occupants were asleep, was considered less risky by them, because there was no merchandise, no fences, and no intermediaries, involved.

The other two of the six subjects in this group who did not mind burgling a residence that was occupied usually broke in during the daytime or early night. Their action was more opportunistic than planned. Both of these suspects claimed that they were often precipitated to commit their crimes by the prior fortuitous sighting of an opportunity, which they then proceeded to exploit.

The reason most frequently mentioned by the subjects in this study, for avoiding an attempt to burgle a residence when it was occupied, was that doing so increased the chance of being seen by the occupants, who then were likely to confront the intruder. Subjects feared such confrontation primarily because the occupants might injure them, or they might injure one or more of the occupants; thus turning what would otherwise have been simple burglary into aggravated burglary, which would carry the possibility of a much heavier sentence if they were caught.

I always made sure that no residents were home.... I tried not to break in a house while somebody was inside. Even if I got that feeling that somebody was in the house, I avoided it, because a face-to-face confrontation with residents could hurt me. (Respondent 10)

They are so unpredictable. You never know if people are armed, or how many people there are in the house. You might meet up with a person with a steel pipe. It's just not worth it at all. (Respondent 27)

You get less time in prison if you are caught for burgling an empty house. If you rob a house, you might get ten years out of it if there is an injury. (Respondent 19)

\subsection{Methods Used to Determine Occupancy}

In general, subjects in the study sample were fearful of encountering an occupant during a burglary, believing that such an encounter might result in increasing the risk of both their own apprehension and also, if apprehended, the severity of the sentence that they would subsequently receive as punishment. Thus, there were various ways in which subjects probed a residence to determine occupancy. In many cases, the techniques that they employed in this connection were used in combination with each other, in order to be certain that the target residence was empty. As one subject described it:

I rang the doorbell first, and then looked into the windows to make sure that the home was not occupied. I do not do a house with anyone in it, because I'm scared of being met when I'm in the house. (Respondent 10)

The most common method of determining residential occupancy used by the subjects was to knock on the door or ring the doorbell. A bit less than half of the subjects (40.4 per cent) referred to this method, claiming that they knocked on the door or rang the doorbell even if they believed the house was empty. If their knock was answered, subjects normally had a stock question ready to ask, the most common one being, according to them, to ask for a fictitious person or address.

If the residents are out, I can sense it. I walk up to the door and ring the bell. If nobody answers, there is nobody in the house. (Respondent 41)

I knock on the front door ready with the questions. If somebody answers, I make up a name and act as if I am at the wrong address. If nobody answers, I commence the burglary. (Respondent 21)

I rang the doorbell on the gate, and when some people answered me, I pretended to be at the wrong address and they directed me to the right address. They were not suspicious of my presence at the house. (Respondent 12)

Seven of the subjects also said that they would break into a house where the curtains were still drawn together during the day, or the newspapers were piled up, unopened, by the front door.

If newspapers or mail are piled up, it is unlikely that there are residents home. However, in order to make sure, I do one or two more things to check. (Respondent 16)

When the curtains or blinds are drawn together during the day, six or seven chances out of ten, there is nobody in the house. It is worth checking whether there is anybody there or not. (Respondent 29)

The sight of a car parked near a house being evaluated as a possible burglary target, would often lead subjects to believe that the house was occupied. Four of them said that they would not choose a house where a car was parked next to it. A car sitting near the house did have an influence on them in the early stages of selecting a house as a burglary target. When these subjects were scanning down an entire street, their eyes were drawn to houses without a car in front.

If there is a car parked near a house, it means that there are residents in the house or near the house. They can come back at any time. (Respondent 42)

These days, people are very lazy and they drive everywhere. Even when they go to a supermarket near 
home, they often drive. If cars are there at the home, they are there too. (Respondent 13)

I don't target a house with a car near it for obvious reasons. A parked car in the driveway is the most obvious sign that indicates residents are in the house. (Respondent 31)

These were some of the obvious clues that even the inexperienced burglars among the subjects could think of as ways of detecting traces of occupancy in a potential residential burglary target; and, in general, occupancy-probe techniques were similar across the subjects in the sample. However, occasionally more creative methods were displayed. Experienced burglars among the subjects often looked for less obvious clues in determining residential occupancy. For instance, one experienced burglar explained that he read the electrical meter before breaking into a home.

I read the electrical meter before hitting a house. When the disc in the gauge meter runs fast, it means someone is in the house. (Respondent 7)

In the prior research, signs of possible residential occupancy have exhibited mixed results when assessed as a deterrent to burglary. For example, Lee [6] and Maguire and Bennett [17] both found that clues signalling an absence of occupancy were highly attractive and influential for burglars. Bennett and Wright [16] on the other hand, found that signs of occupancy were only a marginal deterrence to burglars. Bernasco and Nieuwbeerta [7] also found signs of occupancy unimportant from the point of view of burglar deterrence. In this study, although a few experienced burglars among the subjects preferred, for greater reward, to break into houses when the residents were asleep at night, the vast majority of the subjects were easily deterred by signs of possible residential occupancy; and they tried to make sure that residences that they targeted for burglary, were not occupied when they burgled them. In this connection, subjects in this study employed various techniques to ascertain residential occupancy.

\section{Conclusion}

In this study, subjects looked for residential design features that conformed to their description of what constituted a 'good' residential target. Therefore, the attractiveness of any given potential residential burglary target was shown to depend on the immediate characteristics of the target in question as perceived by the subject. A number of such specified characteristics were found to attract subjects to potential targets. Some of the characteristics or features that attract burglars to particular potential residential targets are the aspects over which the victim, that is, the owner or occupant of the residence in question, has little control. For example, the 'location' of the target, and the 'escape routes' away from it, are characteristics which were considered important by the subjects in this study, but both of these features would be difficult to change unless the residence were somehow relocated. However, it is possible, in terms of burglary prevention, to manipulate some of the other features that belong to a potential targeted residence.

The principle behind these initiatives is that the individual homeowners should seek to reduce the opportunities for burglary against their residences, by increasing the risk of apprehension; and reducing the possible rewards from the burglary. Hence, all these key aspects can render a target that has been thus reinforced in respect to its deterrent features, less appealing to the burglar. However, the subjects in the study sample were generally more influenced by the attendant risks of a proposed burglary, than by its anticipated rewards. Therefore, in the work of burglary prevention in Korea, initiatives should focus more on cues relating to risk rather than to those signals that encourage the burglar's expectancy of significant reward from any given burglary.

Particularly, as demonstrated in this study, burglars regard occupancy of a residence as a primary risk factor in their decision making to commit the crime, creating signs of occupancy, including installation of mock occupancy signals and holding mail or newspapers while away will greatly contribute to reducing and preventing the damage by burglary.

\section{References}

[1] R. V. Clarke and T. Hope, "Coping with Burglary: Research Perspectives on Policy,” Boston: Kluwer-Nijhoff, 1984.

[2] M. Maguire and J. Kynch, "Public Perceptions and Victims' Experiences of Victim Support: Findings from the 1998 British Crime Survey," London: Home Office, 2000.

[3] H. A. Scarr, "Patterns of Burglary," Washington, D.C.: US Government Printing Office, 1973.

[4] D. Walsh, "Victim selection procedures among economic criminals: the rational choice perspective', in D. B. Cornish and R. V. Clarke (eds.), The Reasoning Criminal: Rational Choice Perspectives on Offending," New York: Springer-Verlag Inc, pp. 39-52, 1986.

[5] R. Garcia-Retamero and M. K. Dhami, "Take-the-best in expert-novice decision strategies for residential burglary," Psychonomic Bulletin \& Review, vol. 16, pp. 163-169, 2009.

[6] S. Lee, "The Impact of Home Burglar Alarm Systems on Residential Burglaries," Ph.D. Thesis, The State University of New Jersey, New Jersey, 2008.

[7] W. Bernasco and P. Nieuwbeerta, "How Do Residential Burglars Select Target Areas?: A New Approach to the Analysis of Criminal Location Choice," British Journal of Criminology, vol. 45, pp. 296-315, 2005.

[8] I. Hearnden and C. Magill,"Decision-Making By House Burglars: Offenders' Perspective (Vol. 249)," London: Home Office, 2004.

[9] A. M. Huberman and M. B. Miles, 'Data management and analysis methods', in N. K. Denzin and Y. S. Lincoln (eds.), "Handbook of Qualitative Research," Newbury Park: Sage, 
pp.428-444, 2000.

[10] J. W. Creswell, "Research Design: Qualitative, Quantitative, and Mixed Methods Approaches" (3rd edition), New York: Sage Publication, Inc., 2008.

[11] Korea National Police Agency, "White Paper on Police," Seoul: Korea National Police Agency Printing Office, 2012.

[12] S. Johnson and K. Bowers, "Permeability and Burglary Risk: Are Cul-de-Sacs Safer?," Journal of Quantitative Criminology, vol. 26, pp. 89-111, 2010.

[13] National Institute of Justice, "NIJ Reports No. 287," Washington D.C.: National Institute of Justice, 2010.
[14] I. Waller and N. Okihiro, "Burglary: The Victim and the Public," Toronto: University of Toronto Press, 1978.

[15] T. A. Reppetto, "Residential Crime," Cambridge: Ballinger Publishing Company, 1974.

[16] T. Bennett and R. Wright, "Burglars on Burglary," Hants: Gower, 1984

[17] M. Maguire and T. Bennett, "Burglary in a dwelling: The offence, the offender, and the victim, London: Heinemann, 1982

[18] R. T. Wright and S. H. Decker, "Burglars on the Job: Street Life and Residential Break-ins," Boston: Northeastern University Press, 1994. 